\title{
COMMAND INTERNEURONS IN THE CRAYFISH CENTRAL NERVOUS SYSTEM*
}

\author{
By H. L. ATWOOD† AND C. A. G. WIERSMA \\ Division of Biology, California Institute of Technology, Pasadena, California
}

(Received 24 October 1966)

\section{INTRODUCTION}

Considerable analysis has been made of the properties of individual interneurons in the crayfish central nervous system. Most of the investigations have dealt with the reactions of interneurons to specific sensory stimuli. It has been possible to characterize many of the interneurons both in terms of the sensory information they carry and their position within the nerve cord. Thus the crayfish central nervous system apparently has a very specific organization, which increases the chance that the ways in which it functions may ultimately be understood in some detail.

This possibility is enhanced by the results of studies which deal with the effects of activation of certain interneurons on the motor responses of the animal. Wiersma (1952) found that specific interneurons, when stimulated, gave rise to well-defined motor reactions. The giant fibres, which generate the tail flick, provide the bestknown example; and the 'defence reflex fibre' (Wiersma, 1952) is another. Hughes \& Wiersma (1960) and Wiersma \& Ikeda (1964) studied interneurons (command fibres) causing rhythmic beating of the swimmerets when stimulated at a frequency around $30 / \mathrm{sec}$. They also found interneurons which inhibited these responses. Recently, Kennedy, Evoy \& Fields, (1966) and Evoy (1966) have investigated a number of fibres which evoke various patterns of motor output to the flexor and extensor muscles of the abdomen.

The above studies suggest that there may be many interneurons which control in different ways motor outputs of the lower ganglia (Wiersma, I962). The proportion of the nerve cord constituted by these interneurons, and the way in which their activity is regulated by other neurons, are problems requiring further investigation. In addition, little is known about their natural activity, or about the importance of variations in the activity patterns for the reactions controlled by these interneurons. In the case of the crayfish giant fibres there is a tight coupling between impulses in the interneurons and the motor response; each giant-fibre impulse sets up one impulse in the giant and some other motor axons (Wiersma, I947, 1952; Takeda \& Kennedy, 1964) and repetitive firing in certain other motor axons (Wiersma, 1952). However, in other cases, as between command fibres and motor axons of swimmeret muscles, there is a much less tight coupling. Recently Wilson \& Wyman (1965) have demonstrated that the motor output from the locust thoracic ganglia to the flight muscles has no phase relationship to stimuli applied to the ganglia to initiate the pattern.

\footnotetext{
- Supported by grant GB-278 from the National Science Foundation and grant NB-03627 from the National Institutes of Health, Public Health Service.

$\dagger$ Present address: Department of Zoology, University of Toronto, Canada.
} 
The relative prevalence of direct and indirect coupling between interneuronal activity and motor output can only be determined by further investigations.

The present study was concerned with stimulation of neurons in the circumoesophageal commissures leading from the brain to the lower ganglia, with a view to determine what types of 'command fibres' could be regularly obtained there, in addition to those already known. A further aim was to investigate the effects of varying the pattern of their stimulation on the characteristics of the evoked motor responses.

\section{METHODS}

Specimens of Procambarus clarki (Girard) were glued by the posterior part of the thoracic carapace to a small frame, leaving the limbs and other appendages free to move. The frame was mounted to hold the animal in its normal orientation. The anterior part of the carapace, the stomach, the digestive gland and the green glands were removed to expose the circumoesophageal commissures, which were subsequently desheathed and split into small bundles of neurons (see Wiersma, Ripley \& Christensen, 1955). The animal was kept immersed in van Harreveld's solution at controlled temperatures.

Bundles of neurons from the commissures were stimulated through fine platinum wire electrodes to test for motor responses. Those of interest were split further in an effort to obtain single interneurons still evoking motor reactions. Such interneurons were cut from the brain to ensure direct activation via a descending pathway. In favourable preparations the effects of varying the pattern of stimulation on the motor responses were investigated. Electrical correlates of the motor responses were recorded on magnetic tape through electrodes of insulated no. 40 copper wire, implanted into selected muscles. The records provided general information about the pattern of the electrical response but did not permit complete resolution of the output.

The locations within the commissure of interneurons evoking motor responses were mapped, using the descriptive cross-section of Wiersma (1958).

\section{RESULTS}

\section{A. General features of the preparations}

The responsiveness of the preparations to stimulation of interneurons was influenced by a number of factors, including temperature and time after dissection. Preparations maintained at $10-15^{\circ} \mathrm{C}$. remained responsive for $2-4 \mathrm{hr}$. and did not exhibit excessive spontaneous movement. At temperatures below $10^{\circ} \mathrm{C}$. responsiveness was depressed, while at temperatures much above $15^{\circ} \mathrm{C}$. spontaneous activity was often pronounced, and the preparations did not last as long. Just after dissection the preparations usually responded poorly until they had been in the saline for 10-20 min. As the preparations aged, responsiveness gradually declined and sporadic 'undriven' discharges of motor axons occurred after two or more hours. Changes in the responses to stimulation of isolated interneurons could also be seen at this time. Experimental results were taken only from those preparations maintained at $10-15^{\circ} \mathrm{C}$. which did not show either low responsiveness or excessive spontaneous activity.

In the attempts to identify single interneurons responsible for controlling specific 
motor reactions, several practical difficulties were encountered. Stimulation of isolated single interneurons was necessary in order to definitely establish that a single interneuron was controlling a given reaction. As long as more than one axon was stimulated there was a possibility of interaction. In practice it was often found that a known command fibre stimulated within a small bundle of interneurons produced the same effect as when it was subsequently isolated and stimulated separately. However, the reaction produced by stimulating a small bundle was not assumed to represent the effects of a single command fibre unless the latter could be isolated. Such isolation failed frequently, but was accomplished in many instances. No satisfactory alternative procedure was found although several were attempted.

It was not always possible to distinguish with certainty between effects produced by a genuine command fibre and those arising from stimulation of a central sensory pathway. The criteria used for deciding whether a given interneuron was definitely a command fibre included occurrence in the same place in the connective in a number of preparations and production of a specific motor reaction at a relatively low frequency of stimulation after isolation from the brain. Interneurons of this type appeared to form a relatively small proportion of the total in the connectives. The most useful criterion for locating them was the low frequency of stimulation required to produce their-effects. Further, the responses evoked by them often were dominant over lowlevel activity present in the preparation. As the frequency of stimulation was increased, the probability of any given interneuron producing a motor reaction also increased. However, initial responses produced by stimulation at high frequencies (above $30 / \mathrm{sec}$.) often proved to be labile and inconsistent, and may have represented secondary reactions caused by interneurons or even primary sensory fibres whose output activated a command fibre, rather than a direct stimulation of such a fibre. In the present study attention was confined to those neurons which evoked well-defined responses at stimulation rates below $30 / \mathrm{sec}$. and which could be consistently located.

\section{B. A command system sensitive to frequency and to pattern}

Among the interneurons giving rise to motor activity one was found more readily than any of the others and was studied in more detail. It was obtained in a total of forty preparations and sometimes in both connectives of the same preparation. The fibre was consistently found in area 70 of the commissure (Fig. I). The bilateral motor reactions produced by it at low frequencies of stimulation were quite well defined and consistent. For convenience, this fibre will be referred to by its code number, $\mathrm{CM}_{4}$.

The main features of the reactions triggered by $\mathrm{CM}_{4}$ are shown in Table $\mathbf{I}$. Of special interest is the change in character of the reaction with changes in frequency of the applied stimulation. Thus at stimulation rates of $2-4 / \mathrm{sec}$. the reaction was limited to backward movement of the fifth pereiopods, but at $10 / \mathrm{sec}$. the reaction included flexion of the abdomen and extension of the claws, and at $15 / \mathrm{sec}$. beating of the swimmerets. The various components of the reaction appeared with shorter latency at higher stimulation rates. Claw extension, for example, appeared with a latency of 20-30 sec. at $8 / \mathrm{sec}$., but at $12 / \mathrm{sec}$. the latency decreased to $10 \mathrm{sec}$. and at $15 / \mathrm{sec}$. to $2-5 \mathrm{sec}$. The speed of this and most other reactions also increased with higher rates of stimulation. 
The swimmeret beating, seen at frequencies of stimulation above $\mathrm{I}_{5} / \mathrm{sec}$., resembled in its general features that elicited by fibre $\mathrm{E}$ studied by Wiersma \& Ikeda (I964). The swimmeret beat produced by $\mathrm{CM}_{4}$ and by $\mathrm{E}$ is more rapid than that usually seen in the intact animal. Furthermore, $\mathrm{CM}_{4}$ was located in the same area of the commissure as the main swimmeret-stimulating fibre studied by Hughes \& Wiersma (I960), which previously has been considered as identical with E. It is thus likely that $\mathrm{CM}_{4}$ is identical with these fibres.

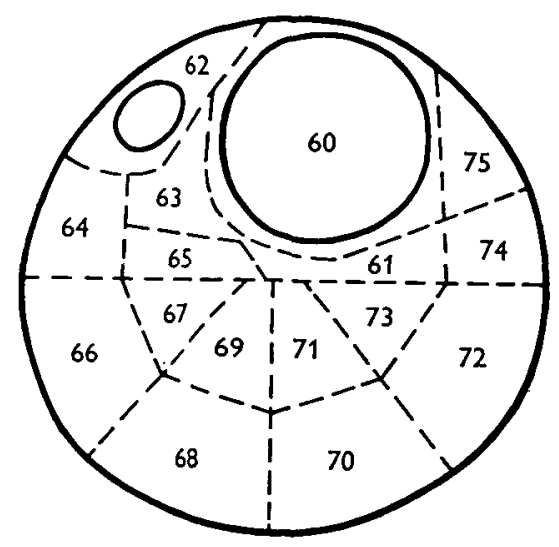

Fig. I. Diagram of a cross-section through the left circumoesophageal commissure showing the location of the numbered subdivisions (Wiersma, 1958).

\section{Table I. Responses to stimulation of $\mathrm{CM}_{4}$ at different frequencies}

\begin{tabular}{|c|c|}
\hline $\begin{array}{l}\text { Frequency } \\
\text { (counts/sec.) }\end{array}$ & Response \\
\hline 2 & Backward rotation of 5 th pereiopods, often in discrete jerks \\
\hline 4 & $\begin{array}{l}\text { More rapid backward movement of } 5 \text { th pereiopods; back- } \\
\text { ward movement of swimmerets; slow flexion of the } \\
\text { abdomen, with simultaneous extension of the telson and } \\
\text { terminal abdominal segment }\end{array}$ \\
\hline Io & $\begin{array}{l}\text { More rapid occurrence of the above reactions; raising and } \\
\text { extension of the claws, and movement to the sides of the } \\
\text { walking legs; 'defence' position }\end{array}$ \\
\hline $15-20$ & $\begin{array}{l}\text { More rapid occurrence of the above, and rapid appearance } \\
\text { of less specific 'struggle' responses; beating of the } \\
\text { swimmerets }\end{array}$ \\
\hline
\end{tabular}

The two swimmeret reactions produced by $\mathrm{CM}_{4}$-the maintained backward retraction at low frequencies and the beat at higher frequencies-were initiated differently. Whereas the rhythmic beat was initiated at the posterior end and propagated forwards (cf. Wiersma \& Ikeda, I964), the retraction occurred nearly simultaneously in all swimmerets. Section of the cord, e.g. between abdominal ganglion 2 and 3 , did not abolish retraction in swimmerets anterior to the cut. It was also noted that several swimmeret beats often appeared immediately after a period of stimulation which induced retraction but no beating.

When $\mathrm{CM}_{4}$ was cut from the brain the reactions would proceed without modification, even when all other interneurons were sectioned and the cut end of $\mathrm{CM}_{4}$ 
stimulated. Section of the nerve cord anywhere along its length did not interfere with or modify any reactions mediated by the ganglia anterior to the cut except for the rhythmic swimmeret movements when made in front of abdominal ganglion 3 . Apparently at least the main features of the reaction do not depend on feedback from posterior ganglia.

A

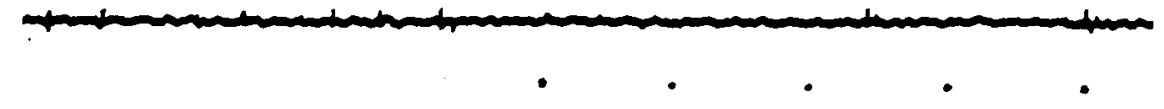

B

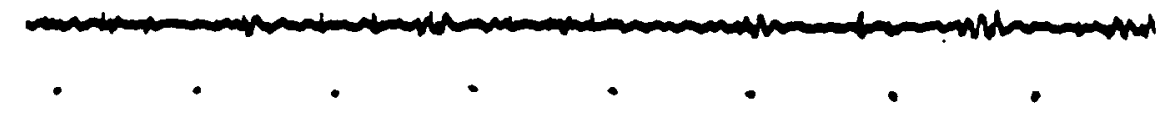

C

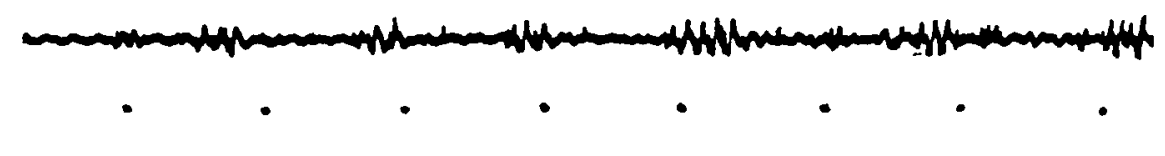

D

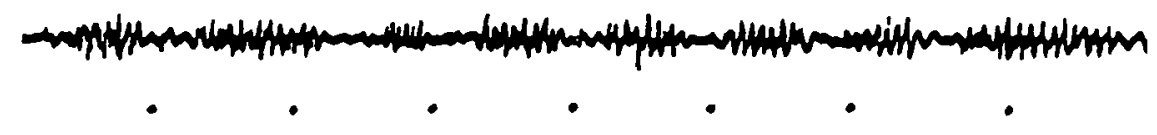

E

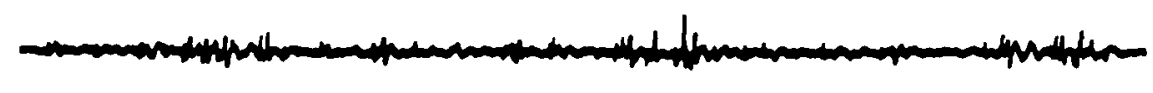

Fig. 2. Excerpts from a record of muscle potentials from the slow abdominal flexors during ro/sec. stimulation of $\mathrm{CM}_{4}$, showing the general features of the electrical output. Stimuli (dots) are $100 \mathrm{msec}$. apart. A, Resting discharge of small muscle potentials, and the start of the stimulation (no immediate response). B, 2 sec. later, showing the start of the electrical response. C, D, Development of the response to its 'steady state: (D) during the course of the stimulation; note increase in amplitude of the muscle potentials and increased average duration of the burst. E, After-discharge bursts.

Some characteristics of the motor output patterns to various muscles were established by recording muscle potentials using implanted wire electrodes. The animal remained able to move its abdominal segments and appendages relatively freely while stimulation was applied.

With regularly spaced stimulation the patterns of the motor outputs to different muscles varied considerably. In the slow flexor muscles of the abdomen small discrete bursts of muscle potentials were recorded, but in other muscles such as the claw extensor the potentials were more evenly distributed.

The output to the slow abdominal flexor muscles was of particular interest, because it could be modified by both the frequency and the pattern of the stimulation applied 
to $\mathrm{CM}_{4}$. The main features of the output, as seen during regularly spaced stimulation, are evident in Fig. 2. Before commencement of the stimulation, there is a 'resting discharge' of small muscle potentials (cf. Kennedy \& Takeda, I965). With stimulation, small bursts of muscle potentials appear after a latency which depends on the rate of stimulation and the condition of the preparation. It was not determined which of the axons described by Kennedy \& Takeda (1965) were responsible for the potentials; probably at least two of the five motor axons were involved, judging from the appearance of the muscle potentials.

A

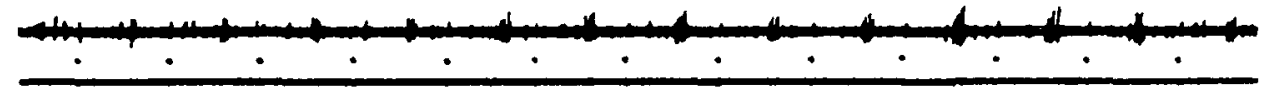

B

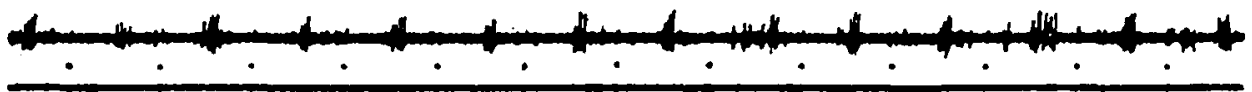

c

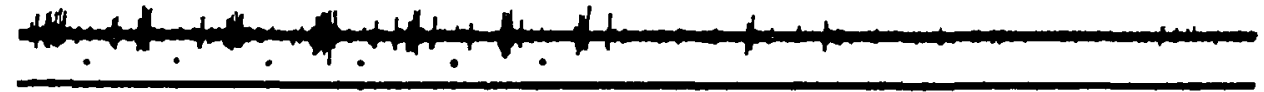

D

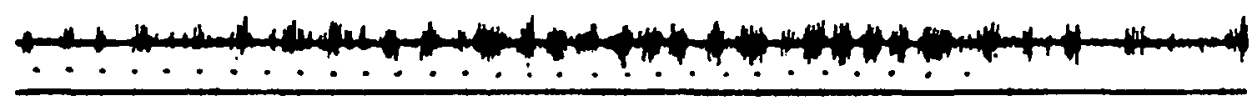

Fig. 3. Influence of frequency of stimulation of $\mathrm{CM}_{4}$ on the muscle potentials recorded in the slow abdominal flexors. A, B, C, Stimulation of $4 / \mathrm{sec}$. (stimuli marked by dots, $250 \mathrm{msec}$. apart). Note increase in size of the potentials during the stimulation. D, Stimulation at $10 / \mathrm{sec}$., showing increased frequency of bursts of potentials.

The frequency of occurrence of bursts of muscle potentials corresponded with the frequency of the input stimulation, from $2-4 / \mathrm{sec}$. up to about $15 / \mathrm{sec}$. (Fig. 3). Above I $5 / \mathrm{sec}$. it was less easy to distinguish the bursts because they became more and more confluent. At the lower frequencies of stimulation a delay of about $100 \mathrm{msec}$. occurred between each stimulus and the succeeding burst (Fig. 3). But individual bursts varied in duration and latency; sometimes two bursts, instead of one, followed a single stimulus. Both the amplitude of the constituent muscle potentials and the burst duration showed an average increase during a train of stimuli (Figs. 2, 3).

Following a period of stimulation, particularly at the higher frequencies, several cycles of after-discharge often occurred (Fig. 2). This phenomenon could be particularly well demonstrated by the application of a short train (100-300 msec.) of closely spaced (ro-20 msec.) stimuli. This treatment elicited several bursts of potentials, at a rate of about $15 / \mathrm{sec}$, , occurring immediately after stimulation. In addition, a continuing low frequency of stimulation, which by itself produced small or infrequent bursts, evoked large bursts of sizeable muscle potentials when given after a short period of high-frequency stimulation. These results illustrate that a given motor output can be set up by more than one pattern of activity in a command fibre.

Electrodes inserted into the slow flexor muscles in separate segments $(2-5)$ of the 
abdomen invariably picked up similar patterns of muscle potentials in all locations when $\mathrm{CM}_{4}$ was stimulated.

By varying the pattern of the stimuli the output to the slow flexors could be modified to some extent. For a given frequency of stimulation the electrical output was different, depending on whether the stimuli were evenly spaced in time, or given in closely spaced pairs. In the latter case the discrete, regularly occurring bursts of potentials resulting from evenly spaced stimuli tended to coalesce into longer, but less frequently occurring bursts (Fig. 4). A correlated change was observed in the mechanical response of the abdomen, which changed from a slow, smooth flexion to one which proceeded in a series of small jerks. The spacing between the pulses of a pair had to be greater than $7 \mathrm{msec}$. for the second stimulus to have an effect. With closer spacings the electrical and mechanical responses were similar to those produced at half the average frequency of stimulation.

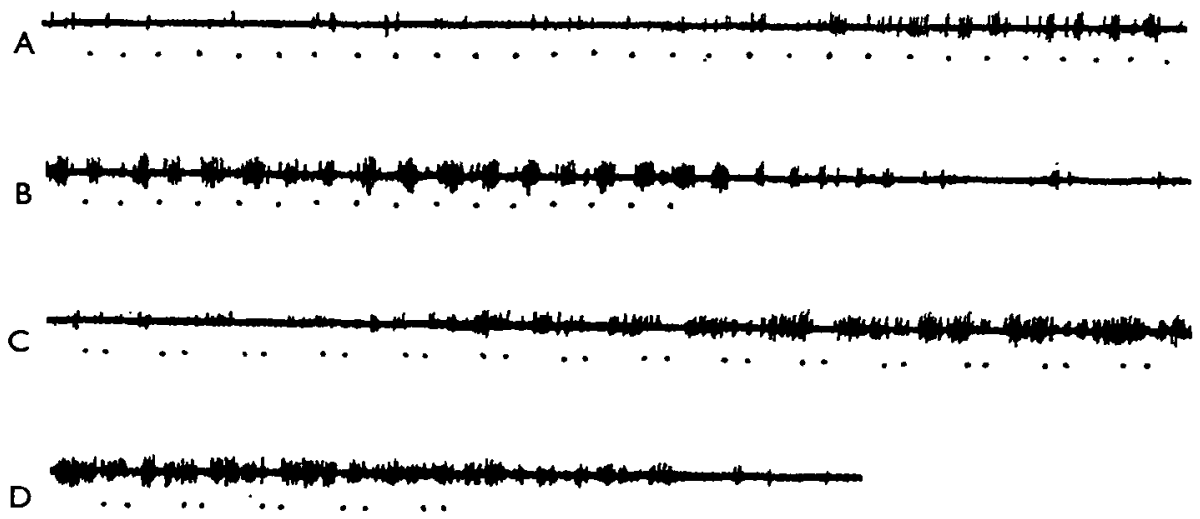

Fig. 4. Influence of stimulus spacing on the motor output to the slow abdominal flexors. A, B, Stimuli (dots) delivered at $8 / \mathrm{sec}$. (I $25 \mathrm{msec}$. apart), even spacing. Note regular bursts of potentials. C, D, Stimuli delivered at an average frequency of $8 / \mathrm{sec}$. but with uneven spacing (intervals of 40 and $85 \mathrm{msec}$.). Note longer and less regular bursts of potentials.

The position of the abdomen did not seem to exert much influence on the electrical output to the slow flexors triggered by $\mathrm{CM}_{4}$. When the abdomen was held extended, the signals were usually of smaller amplitude but of the same pattern. Differences in amplitude may have been due to shifts in position of the recording electrodes relative to the responding muscle fibres.

In a number of preparations, where $\mathrm{CM}_{4}$ was found in both connectives, stimuli were applied synchronously or with various temporal phase differences to the two fibres. Each fibre elicited the same characteristic electrical and mechanical responses in the slow abdominal flexor muscles, although one fibre often appeared to be more effective than the other at a given frequency. Stimulation at $4 / \mathrm{sec}$. applied to each fibre $180^{\circ}$ out of phase with its partner produced a reaction like that generated by $8 / \mathrm{sec}$. stimulation applied to one fibre. When the stimuli were applied to both sides synchronously, or within 6-7 msec. of each other, the result was like that obtained with $4 / \mathrm{sec}$. stimulation given to one fibre; in other words, one of each pair of nerve impulses had no effect. Thus the two fibres have at some point a common connexion 
with a refractory period of $5-7$ msec., which may be at the same locus responsible for the refractory period of the same length found when only one fibre is stimulated.

Among the other muscles recorded from during stimulation of $\mathrm{CM}_{4}$ those at the base of the fifth pereiopod showed an electrical response similar to that of the slow flexors, i.e. discrete bursts of small muscle potentials. This response appeared, however, with a shorter latency, in accordance with the earlier mechanical activity.

By contrast, the output to a number of other muscles, including the extensors of the carpopodite in the chelae, showed a less well-defined pattern. The output of these muscles showed a higher average frequency when the stimulation frequency was increased, but there was seldom any well-defined temporal relationship between the output and the stimuli. Fig. 5, a record from a carpopodite extensor, shows that the spacing of the muscle potentials during claw extension is not even; closely spaced doublets and triplets of potentials occur frequently.

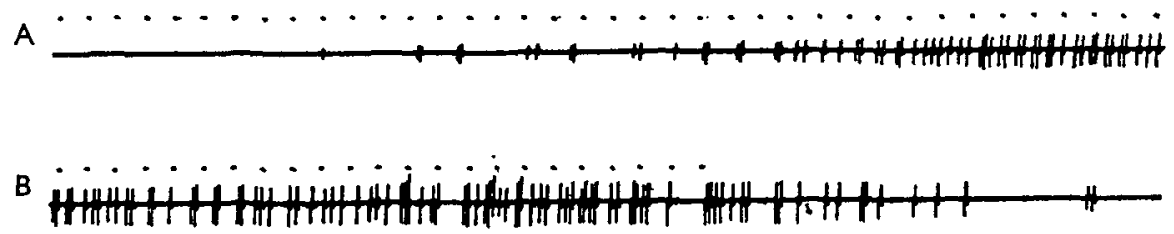

Fig. 5. Discharge of potentials recorded from the claw extensor muscle during stimulation of $\mathrm{CM}_{4}$ at $8 / \mathrm{sec}$. (dots, $125 \mathrm{msec}$. apart), showing lack of grouped bursts of potentials as in the slow abdominal flexors, but a strong tendency to fire in groups of 2 and 3 .

A similar spacing of muscle potentials has been described by Wilson \& Davis (1965) for the opener muscle of the crayfish claw. Following their method an interval histogram of the $\mathrm{CM}_{4}$-evoked output to the carpopodite extensor was plotted, in which the time-intervals between successive impulses were measured and the frequency for each interval was tabulated. The histogram was markedly bimodal, with peaks occurring for intervals of $5-9 \mathrm{msec}$. and $34-38 \mathrm{msec}$. This result is in close agreement with that obtained by Wilson \& Davis (1965) for the claw opener muscle during intermediate levels of activity. When the patterns of potentials set up by $\mathrm{CM}_{4}$ stimulation were compared with those caused in this muscle by various sensory stimuli applied to the freely moving animal, they were found to be similar. It therefore appears that this type of pattern formation may play a considerable role in a number of reflex responses involving this and other muscles.

\section{Other motor output systems}

In the circumoesophageal commissures a number of other command fibres were found frequently enough to permit considering them as definite entities. The reactions produced by a number of these fibres are briefly described below, and will illustrate some of the variability and similarity between different systems.

Information on the location, minimum effective stimulation frequency, and initial reaction produced by each fibre is summarized in Table 2 .

Fibre $C M_{5}$ produced responses to stimulation at $10-15 / \mathrm{sec}$. with a latency of several seconds. The initial response consisted of lowering and downward 'groping' 
of the third homolateral pereiopod; the terminal segments (dactyl and propodite) were also moved. With continuing stimulation, or at a higher frequency, the fourth homolateral pereiopod was raised and pointed obliquely upwards. The fifth homolateral pereiopod was also raised with continued stimulation, but neither as strongly nor as high as the fourth. With still longer periods of stimulation at frequencies of $20-30 / \mathrm{sec}$. the other legs and claws, both homo-and heterolateral, were raised and moved. All reactions were weaker on the heterolateral side.

This fibre provides an example of a reaction driven more strongly on the homolateral side of the body, in contrast with $\mathrm{CM}_{4}$ which elicited symmetrical responses. The evoked reaction is similar to that often elicited when an intact crayfish is grasped by the sides of the carapace and picked up.

Table 2. Properties of eight command fibres in the circumoesophageal commissure

\begin{tabular}{|c|c|c|c|c|}
\hline Fibre & Area & $\begin{array}{l}\text { Times } \\
\text { found }\end{array}$ & $\begin{array}{l}\text { Minimum } \\
\text { effective } \\
\text { frequency } \\
\text { (counts/sec.) }\end{array}$ & Initial reaction \\
\hline $\mathrm{CM}_{4}$ & 70 & 40 & $2-4$ & $\begin{array}{l}\text { 5th pereiopods back; swimmerets back; slow flexion } \\
\text { of abdomen. (Table I) }\end{array}$ \\
\hline $\mathrm{CM}_{5}$ & $64-66$ & 6 & $10-15$ & $\begin{array}{l}3^{\text {rd }} \text { homolateral pereiopod down; } 4 \text { th homolateral } \\
\text { pereiopod up }\end{array}$ \\
\hline CM6 & $63-65$ & 3 & Io & Rhythmic leg movement \\
\hline CM8 & 72 & 8 & $4-10$ & $\begin{array}{l}\text { Extension of abdomen, leg movement, forward claw } \\
\text { rotation }\end{array}$ \\
\hline $\mathrm{CM}_{9}$ & 75 & 5 & IO-1 5 & Forward rotation of claws and legs \\
\hline CMro & 75 & 3 & 20 & Raising of claws, 'defence reflex' \\
\hline CM I I & $62-63$ & 8 & $10-15$ & Flexion and closing of homolateral claw \\
\hline $\mathrm{CM}_{12}$ & 62 & 6 & 15 & Raising of claws with partial flexion; leg movement \\
\hline
\end{tabular}

Fibre CM6 initiated walking movements of the legs when stimulated at frequencies greater than $\mathrm{ro} / \mathrm{sec}$. The legs were held out sidewards, and rotated rhythmically from forward to backward at the basal joint, as well as being alternately flexed and extended by the muscles in the meropodite. No discernible pattern of co-ordination between the different legs existed; each seemed to move with an independent rhythm. At frequencies from 20-40/sec. the rate of movement of the limbs speeded up with increasing frequency of stimulation. Above $40 / \mathrm{sec}$. tail flaps, claw movements and other 'struggle' responses often occurred.

This fibre may serve normally as a general initiator of walking; but whether the response could be modified by feedback from sense organs was not determined.

Fibre $C M 8$, when stimulated at 4-10/sec. and higher, initiated a reaction which included among its components, in order of their appearance: extension of the abdomen; holding of the legs in a lateral, downward-directed position, with subsequent movement (mainly in the dorso-ventral plane); forward rotation of the claws, with subsequent downward movements; and in some cases, beating of the swimmerets and scaphognathites. With increasing frequency of stimulation the frequency of leg and claw movements increased, and 'struggle' responses could result from prolonged stimulation at the higher frequencies. Usually there was marked persistence of the reaction following stimulation. 
Fibre $C M 9$, when stimulated at $\mathrm{IO}^{-1} 5 / \mathrm{sec}$., caused bilateral forward rotation of the claws and legs, the homolateral reactions being slightly stronger. Continued stimulation often resulted in slow extension of the abdomen, followed by flexion, and in nonspecific leg movements and 'struggle' reactions.

Fibre $C M$ ro produced a defensive posture when stimulated at frequencies greater than $20 / \mathrm{sec}$. The claws were raised and extended, the legs held out from the sides, and the abdomen partly flexed. With increase in the frequency of stimulation the speed of the reaction was greater. This fibre may be the 'defence reflex fibre' described previously by Wiersma (1952), which is located in area 75 (see Wiersma \& Mill, 1965). However, there may be more than one such fibre in this area.

Fibre $C M_{\text {II }}$ initiated responses at frequencies of IO-1 $_{5} / \mathrm{sec}$. and above. The component appearing earliest at the lower effective frequencies was flexion of the homolateral cheliped. Coupled with this, after a delay (or at higher frequencies without a noticeable delay), was closing of the claw, and raising followed by lowering of this appendage. At the higher frequencies ( $30 / \mathrm{sec}$. and above) the homolateral legs also were flexed and raised, then lowered, and the reaction involved, less strongly, the other side of the body. With prolonged stimulation non-specific 'struggle' reactions ensued.

Fibre $C M$ I2 produced a modification of the 'defence' reaction which is sometimes also seen in the normal, freely moving animal. The claws were raised, but held partly flexed, bent, and closed. They were not extended forward, but instead held elevated in such a way that the terminal chelae were aligned horizontally and parallel to the carapace. The legs were raised, then extended sideways and moved mainly in the dorso-ventral plane. The abdomen was usually partially flexed. Movement of the maxillipeds and beating of the swimmerets were also observed. At the lower frequencies of stimulation the reaction was somewhat stronger on the homolateral side.

The fibres listed above are a representative sample of the command fibres found; a number of others were found more than once, but the reactions they evoked under different stimulating conditions were less well defined.

In a few preparations inhibitory fibres, such as those described by Wiersma $\&$ Ikeda (1964) for swimmeret movements, were found. One of these, not previously described, inhibited spontaneous walking movements, but not swimmeret beating.

\section{DISCUSSION}

The findings of chief interest in the present paper are: first, that command fibres in the circumoesophageal commissures generally exert widespread effects; and secondly, that the frequency, and in one case $\left(\mathrm{CM}_{4}\right)$ at least, the fine pattern of stimulation applied to a command fibre, have important consequences in terms of the motor responses elicited. Generally, different components of a given reaction appeared sequentially during the course of stimulation or with increase in its frequency.

The majority of the fibres studied here apparently had connexions in most of the lower ganglia. $\mathrm{CM}_{4}$, for example, which as stated may be identical with the swimmeretdriving fibre of Hughes \& Wiersma (1960) and fibre E of Wiersma \& Ikeda (1964), was found to cause reactions in the limbs and abdominal musculature as well as in the swimmerets. The different muscles controlled by $\mathrm{CM}_{4}$ could be activated 
serially by manipulation of the frequency and duration of the stimulation. The normal animal should be able to bring about movement of the fifth pereiopods or a fullfledged defence reaction, by varying the activity in $\mathrm{CM}_{4}$. Further modification of the reactions caused by this as well as other command fibres could be achieved through activity of inhibitory interneurons which selectively affect segments of the total response. For example, activity in one of the swimmeret-inhibiting fibres (Wiersma \& Ikeda, I964) during a $\mathrm{CM}_{4}$-evoked reaction could suppress the swimmeret beat, while possibly allowing the other phases of the response to proceed unaffected. The extent to which use is actually made of the above potentialities has yet to be determined, though the results of Kennedy \& Takeda (1965) on the presence of central inhibitory fibres for the motor output of the abdominal musculature show that these possibilities are not limited to the swimmeret movements.

It is apparent also that more than one command fibre may initiate a given motor reaction, or variations of it. Of the fibres described above, $\mathrm{CM}_{4}, \mathrm{CM}_{1}$ o and $\mathrm{CM}_{12}$ all produced reactions of the 'defence' type; but there were differences in detail. Another example of convergence is provided by the five fibres which elicit swimmeret beating (Wiersma \& Ikeda, 1964). Kennedy et al. (1966) also have found the same feature among command fibres governing the crayfish abdominal musculature.

In considering the command fibres described here, and some of those known from previous work, it appears that they control the output of the motor centres in various ways, some of which have been discussed previously (Wiersma, I962). At one end of the spectrum are the giant fibres, which produce a phasic reaction (the tail flip) with each stimulus. The reaction follows the pattern and frequency of the stimulus with great fidelity. Associated with this situation is a minimum of complication in the connexions between the command fibre and the motor cells.

Fibre $\mathrm{CM}_{4}$ presents a more complicated situation. Some of the reactions set in motion by it (movement of the fifth pereiopods, flexion of the abdomen) are governed to a large extent by both the frequency and the fine pattern of the command-fibre discharges. Other components (e.g. claw extension) are governed mainly by frequency and still other components (swimmeret beating) are relatively insensitive to frequency above the minimum necessary for the effect.

The processes underlying the various response patterns in the motor output channels are, at present, largely unknown. There are presumably a number of transmitting mechanisms involved. The doublets and triplets of impulses, found in the motor fibres of, for example, the carpopodite extensor muscle of the cheliped, probably result from specific properties of the motor neurons, as in the case of motor fibres in abdominal ganglia when 'multiplications' occur. In the latter instance there is direct driving by command-fibre impulses, but in the former case this may not be so.

At present, the labelling of an interneuron as a 'command fibre' signifies only that its activity calls into play a readily recognizable behavioural act. The term is of convenience for descriptive purposes and presupposes very little concerning the details of the mechanisms by which the motor axons are excited. These mechanisms may range in complexity from the direct coupling involved in the giant-fibre synapses to systems in which complex neural pacemaker and timing circuits are interposed between the command fibre and the motor axons. It is also possible (as in the case of 
$\mathrm{CM}_{4}$ ) that a single command fibre may utilize more than one type of circuit to activate the various motor axons under its control.

The reactions evoked by some command fibres apparently represent rather generalized 'blocks of behaviour'. For instance, the fibres eliciting 'walking' (of which CM6 is one) did not produce well-coordinated patterns (in contrast with swimmeretactivating fibres, which evoke a well-coordinated response). Of course, the experimental conditions did not provide the animal with a normal situation. Presumably in cases of this sort the overall response in a normal situation could be modified by sensory feedback, depending on the actual circumstances for each of the different body parts involved. Thus the command fibre may serve to set the initial response and to maintain excitability, but the course of the reaction may depend strongly upon sensory input. At present it appears that especially the struggle reactions which occur in several cases on high-frequency stimulation may be a result of the lack of feedback caused by the absence of leg support. Such reactions are often seen in normal animals lying on their backs. In general, interactions between specific command systems and local sensory inputs invite further exploration.

It is of interest that some fibres of the 'command' type were found to have a high threshold to sensory activation, as observed also by Kennedy et al. (1966). Simultaneous input from a number of different sensory inputs may normally be required to make them respond. To use an electrical analogue, they may have 'AND gate' properties. If so, then many of the interneurons previously investigated are probably not of the command type (cf. Wiersma, 1958), although many of them will function as the input channels for the command fibres. The latter probably constitute a relatively low percentage of the total interneurons.

\section{SUMMARY}

I. The motor effects evoked by stimulation of each of eight command fibres in the circumoesophageal commissures of the crayfish are described.

2. The fibres obtained appeared to have widespread connexions in all or most of the lower ganglia. For certain fibres the response was stronger on the homolateral side of the animal; for others it was symmetrical.

3. The frequency of stimulation of a command fibre generally had a pronounced influence on the speed of the evoked response. In addition, segments of the total response could be elicited selectively by alteration of the frequency and duration of stimulation.

4. Although the responses associated with most of the fibres were not sensitive to the fine temporal pattern of the applied stimulation, for one fibre the motor output depended clearly on the spacing of the stimulating pulses. 


\section{REFERENCES}

Evoy, W. H. (1966). Central commands for postural control in the crayfish abdomen. In Invertebrate Nervous Systems, ed. C. A. G. Wiersma. University of Chicago Press. (In the Press.)

Hughes, G. M., \& Wiersma, C. A. G. (1960). The coordination of swimmeret movements in the crayfish, Procambarus clarkii (Girard). F. exp. Biol. 37, 657-70.

KenNedy, D., Evoy, W. H. \& FiedDs, H. L. (1966). The unit basis of some crustacean reflexes. Symp. Soc. exp. Biol. 20, (In the Press.)

KENNEDY, D. \& TAKEDA, K. (1965). Reflex control of abdominal flexor muscles in crayfish. II. The tonic system. Y. Exp. Biol. 43, 229-46.

TAKEDA, K. \& KENNEDY, D. (1964). Some potentials and modes of activation of crayfish motoneurons. F. cell. comp. Physiol. 64, 165-82.

Wrersma, C. A. G. (1947). Giant nerve fibre system of the crayfish. A contribution to comparative physiology of synapse. $\mathcal{F}$. Neurophysiol. 10, 23-38.

WIERSMA, C. A. G. (1952). Neurons of arthropods. Cold Spring Harb. Symp. quant. Biol. 17, ${ }_{55}-63$.

WIERSMA, C. A. G. (1958). On the functional connections of single units in the central nervous system of the crayfish, Procambarus clarkii (Girard). F. comp. Neurol. 110, 42 I-71.

WIERsMA, C. A. G. (1963). The organization of the arthropod central nervous system. Am. Zool. 2, $67-78$.

WIERSMA, C. A. G. \& IKEDA, K. (1962). Interneurons commanding swimmeret movements in the crayfish, Procambarus clarkii (Girard). Comp. Biochem. Physiol. 12, 509-25.

WIERSMA, C. A. G. \& Mill, P. S. (1965). 'Descending' neuronal units in the commissure of the crayfish central nervous system; and their integration of visual, tactile and proprioceptive stimuli. $\mathcal{F}$. comp. Neurol. 125, 67-94.

Wiersma, C. A. G., Ripley, S. H. \& Christensen, E. (1955). The central representation of sensory stimulation in the crayfish. F. cell. comp. Physiol. 46, 307-26.

Wilson, D. M. \& Davis, W. J. (I965). Nerve impulse pattern and reflex control in the motor system of the crayfish claw. F. exp. Biol. 43, 193-2 10.

WILSON, D. M. \& WYMAN, R. J. (I965). Motor output patterns during random and rhythmic stimulation of locust thoracic ganglia. Biophys. F. 5, $121-43$. 